\title{
TOWARDS AN AUTOMATIC METEOROLOGICAL FORECAST VERIFICATION SYSTEM FOR THE STATE HYDROMETEOROLOGICAL SERVICE, REPUBLIC OF MOLDOVA
}

\section{Raluca Pomaga ${ }^{1}$, Marius-Victor Birsan ${ }^{1 \dagger}$, Ghennadii Roșca ${ }^{2}$, Tatiana Dabija ${ }^{2}$}

Key words: weather forecast; automated verification system; performance scores; forecast quality; Republic of Moldova.

\begin{abstract}
This paper presents a user-friendly application developed for assessing the quality of the meteorological forecasts issued by the Moldavian State Hydrometeorological Service (SHS). The scores are calculated using a method developed at Meteo Romania (National Meteorological Administration), which has been running operationally since 1996. The meteorological elements evaluated in this verification system are: cloud cover, wind speed, fog, glazed frost, hail, frost, minimum and maximum air temperature, as well as the appearance, shape, distribution and intensity of precipitation. The automatic weather forecasting verification system is based on two graphical interfaces, both of them having a specific role in simplifying the user interaction with the database where the information is stored. This work was realized within the World Bank project «Development of a standardized verification mechanism and QMS for the Moldova SHS».
\end{abstract}

\section{Introduction}

Verifying weather forecasts is the process of determining their quality. Some aspects supporting the importance of this process in the operational work concern the monitoring and improving of the quality of forecasts, as well as the posibility to compare the output provided by different forecasting systems.

Weather is one of the most important factors influencing the quality of human life. Despite all efforts and progress made wihtin the last decades in improving the weather forecast quality, it still remains a difficult task, mainly

\footnotetext{
${ }^{1}$ Meteo Romania (National Meteorological Administration), Bucharest, Romania. ${ }^{\dagger}$ corresponding author:marius.birsan@gmail.com

${ }^{2}$ State Hydrometeorological Service, Chisinau, Republic of Moldova.
} 
regarding severe weather and extreme events, with high risk, due to the complexity of the atmospheric processes and their various interactions.

The process of assessing the quality of a forecast represents the forecast verification. It is realized by comparing the forecast with a corresponding set of observation synchronous in time and space (Jolliffe and Stephenson, 2011; Jolliffe and Jolliffe, 2012). This process is extremely important in the operational weather forecasting activities, as it allows to monitor and improve the forecasts quality, as well as to compare the solutions provided by different forecasting systems.

The Republic of Moldova has a temperate-continental climate, influenced by the proximity of the Black Sea, which gives it a mild and sunny climate, and by interferences of warm humid air from the Mediterranean. Climatic seasons are clearly defined with a short low-snow winter and a long summer, sometimes very hot and dry. Through geographical location and natural characteristics, the territory of Moldova is affected more frequently by the following hazards: droughts, heavy rainfall - sometimes accompanied by hail and strong wind gusts -, floods, long-lasting heat temperatures in summer or too low in winter, heavy snowfalls, and early autumn or late in the spring frosts, cases of excessive rime ice formation.

In the last years, because of climate change, these extreme phenomena have become more frequent and intense.

Here we present a user-friendly application developed for assessing the quality of the meteorological forecasts issued by the Moldavian State Hydrometeorological Service. Since Romania and the Republic of Moldova are neighbouring countries, sharing many climatic features, the methodology was considered appropriate to be implemented at SHS. In Romania, recent studies show increases in warm thermal extremes (Birsan et al. 2019), decreasing wind speed (Birsan et al. 2013), and increasing rain shower frequency (Manea et al. 2016; Busuioc et al., 2016), affecting water resources (Birsan, 2015), forest ecosystems (Mihai et al., 2018a,b) and human health (Dobrinescu et al, 2015). In Moldova, Corobov et al. (2010) found upward trends in air temperature since the '80s; Potop and Soukup (2009) discovered an increase in tendencies of frequency and intensities of droughts for the same period.

The automatic weather forecasting verification system is based on two graphical interfaces, both of them having a specific role in simplifying the user interaction with the database where the information is stored. This application is easily transferable, and it can be installed on different operating systems (e.g., Windows, Linux, Mac OS X). 


\section{Methods}

The first and most important stage in the development of a verification system is the collection of prognostic data sets and diagnosis/observations. Interest is also given to the spatial and temporal dissemination of data.

While meteorological forecasts might vary in terms of form and content, it is mandatory that all of them refer to the following parameters: cloud cover, precipitation, wind, air temperature. Special phenomena are evaluated only when they have been predicted and/or they have occurred. Therefore, the meteorological elements evaluated in this verification system are: cloud cover, wind, fog, glazed frost, hail, frost, minimum or maximum air temperature, as well as appearance, shape, distribution and intensity of precipitation.

The scores are computed using the approach applied at Meteo Romania (Romania's national weather service) since 1996 (Colls et al., 1981; Diaconu and Sima, 2001).

To each component of the forecast is given a weighting factor according to its importance. Also, within each component, the associated classes are characterized by different weights, depending on the severity of the production/non-production of the corresponding phenomenon. Weights were established based on specialized documentation, WMO recommendations and feedback from weather forecasters.

As a general rule, the forecast of a non-occurring event is penalized in the same way as the non-forecasting of an event that occurred. Hence, the score depends both on forecasts and on observations. In the meteorological forecasts, the expression "there are conditions for the occurence of a phenomenon" is quite often present. This is considered to correspond to a probability of more than $50 \%$ and it was granted half of the score attributed to categorical forecasts (Yes / No).

The scores are calculated daily for each 24,48 , or 72 -hour forecast ranges, for each region. The tool also computes the country average score as the average of the forecast scores for the considered regions.

Each component $J$ of the forecast (cloud cover, precipitation, etc.) is characterized by:

- the maximum possible score of the forecast: (SMP $(\mathrm{I}, \mathrm{J}), I=1,2)$ where $I$ represents the region;

- the score achieved, depending on the forecast reported to the diagnosis: $(\mathrm{SR}(\mathrm{I}, \mathrm{J}), I=1,2)$.

The score of component $J$ for region $I$ (reflecting the accuracy with which component $J$ was predicted) is obtained as follows: 


$$
\mathrm{SP}(\mathrm{I}, \mathrm{J})=100 \frac{\mathrm{SR}(\mathrm{I}, \mathrm{J})}{\operatorname{SMP}(\mathrm{I}, \mathrm{J})}
$$

The score for region $I$ is defined as:

$$
\operatorname{STP}(I)=100 \frac{\sum_{\mathrm{J}=1}^{N} \operatorname{SR}(\mathrm{I}, \mathrm{J})}{\sum_{\mathrm{J}=1}^{N} \operatorname{SMP}(\mathrm{I}, \mathrm{J})}
$$

where $N$ is the number of forecast components.

The score for component $J$ of the forecast is defined as:

$$
\operatorname{STP}(J)=100 \frac{\sum_{\mathrm{I}=1}^{2} \operatorname{SR}(\mathrm{I}, \mathrm{J})}{\sum_{\mathrm{J}=1}^{2} \operatorname{SMP}(\mathrm{I}, \mathrm{J})}
$$

Using the scores given to each component, the maximum possible score and the realized score are calculated for each meteorological item, for each region. The final results include:

- the forecast score for each meteorological item, for each region;

- the forecast score for each meteorological item, for the whole country;

- the average score for each region;

- the average country score.

\subsection{Data recorder and computation of scores}

The automatic weather forecasting verification system developed described in this paper is based on two graphical interfaces, both of them having a specific role in simplifying the user interaction with the database where the information is stored.

Therefore, the graphical interface (Figure 1) through which the information about diagnosis and meteorological forecasting is entered into the database consists of the following:

- on the left-hand side of the page there is a button that directs the user to the official site of the Hydrometeorological Service of the Republic of Moldova.

- there is also a button that points the user to the page for viewing the forecasting scores.

On the upper left side there is the "INFO" button: by clicking on it, a 
table will appear on the screen describing how to encode the information in the database. Hovering (mouse-over) a cell corresponding to a meteorological phenomenon, an explanatory text area box will appear in which the meaning of the code is displayed. The ranges for each class of precipitation intensity are also detailed (Figure 2).

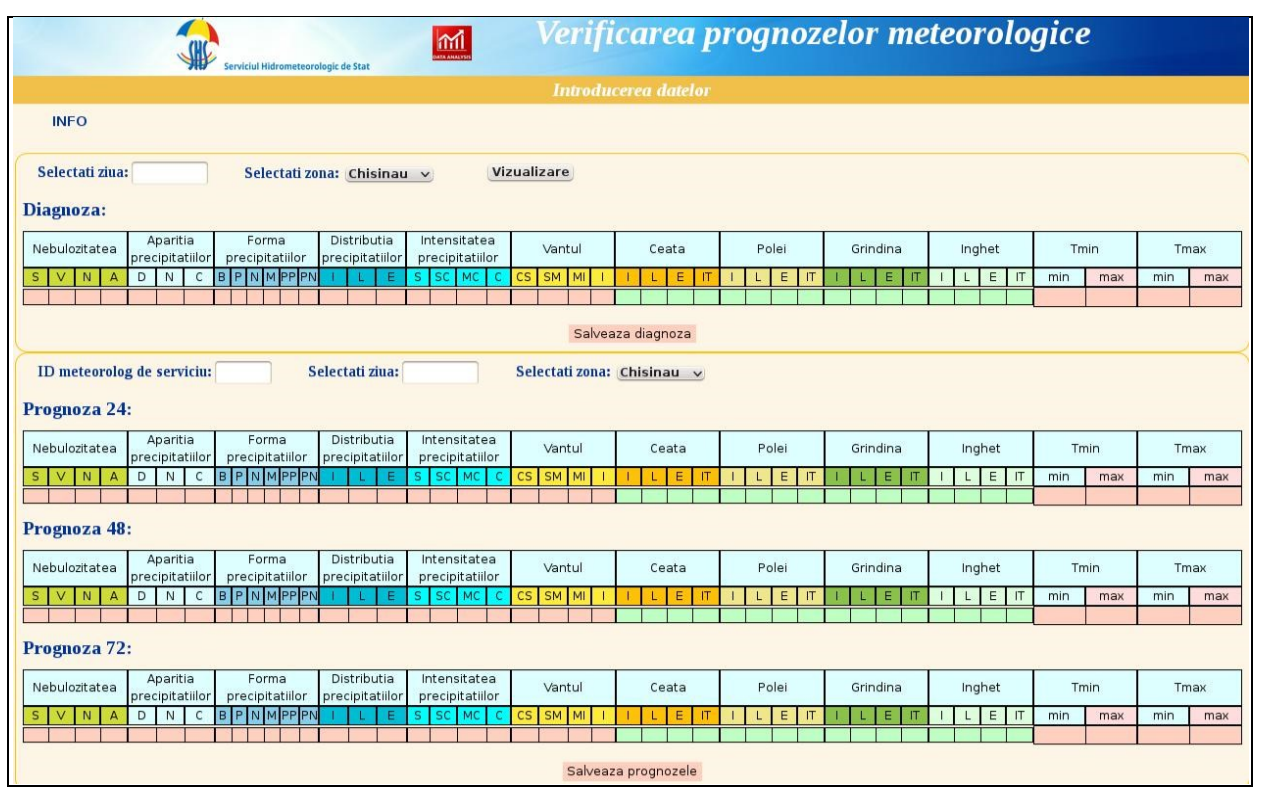

Figure 1. The graphical interface for recording data in the database

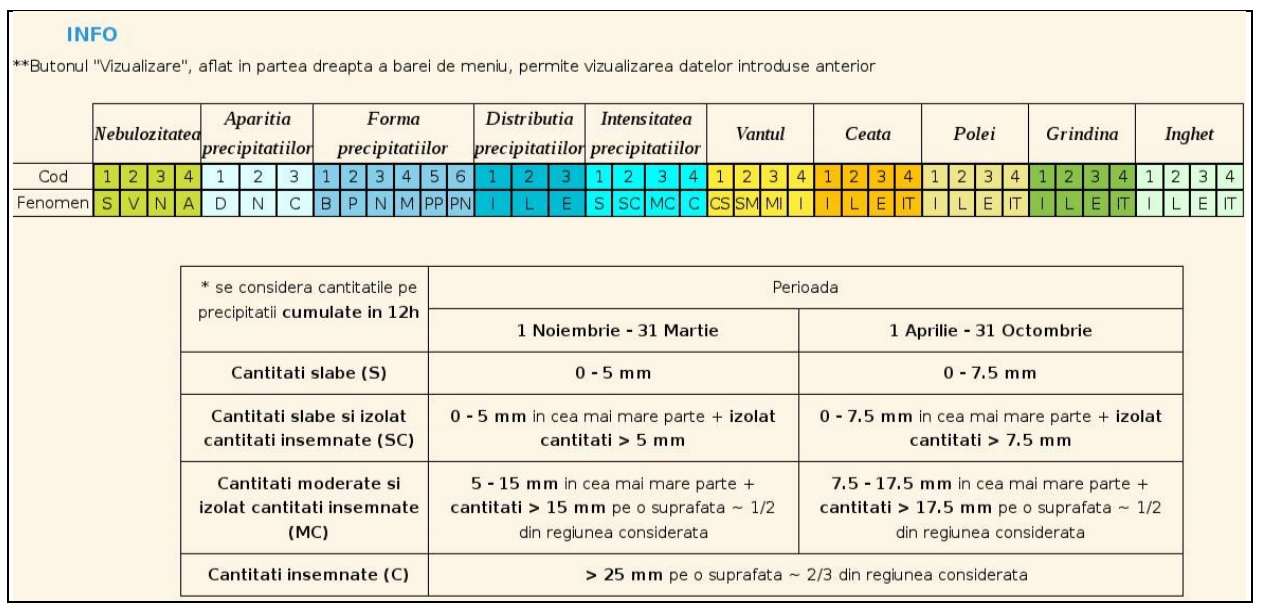

Figure 2. Display mode of the informational table attached to the "INFO" button. 
Two separated forms were created to record the data - one for diagnosis and one for forecasts. Therefore, the diagnosis recording (Figure 3) is done independently of forecasts, which allows for a rapid update of information when the observation data from meteorological stations were not analyzed in a timely manner. On the first use of the application, in order to record a diagnosis, a verification database will be created. Inside this database, five tables are generated, one for diagnosis, three for the forecasts with different anticipation times, and one for scores.

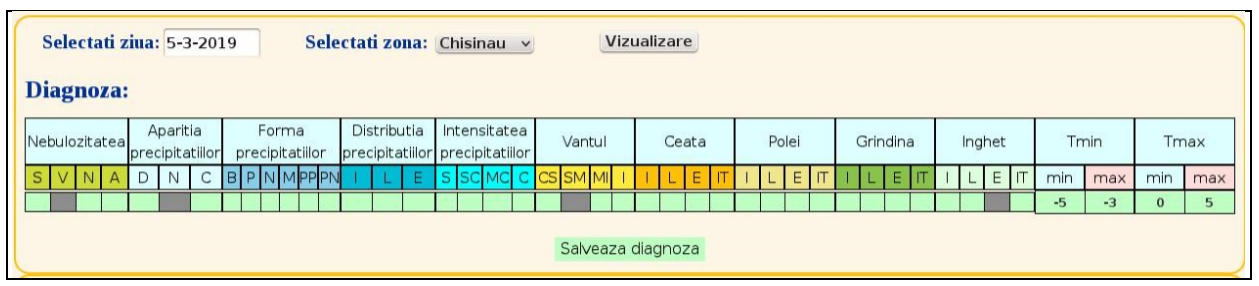

Figure 3. The way of entering diagnosis data in the database.

First, in order to record the diagnosis into database it is necessary to select the day and region. Since the diagnosis is considered to be valid at 06.00 UTC current day, it is not allowed to select a future day. As far as the selection of the region is concerned, there are two options: Chisinau and Republic.

Then, the information about diagnosis will be recorded by filling the associated table. Completing the table will be done by clicking the button related to the phenomenon that has taken place.

If "No Precipitation" is selected in the "Precipitation" field, the buttons associated with shape, distribution, precipitation intensity and hail are blocked and the information is automatically valid. For warm season, the meteorological item "Form of precipitation" is not evaluated. Thus, for this period, the buttons associated with it are blocked, and it is also allowed to enable the save button.

The data will be saved in the database by pressing the "Salveaza diagnoza" ("Save the diagnosis") button at the bottom of the table. The activation of this button is related to the compliance of some rules:

- it is not allowed to select the "Conditions" button for the appearance of precipitation;

- the maximum value of the maximum temperature must be higher than all other values;

- the maximum value of the minimum temperature must be greater than the minimum temperature;

- the input values must be within the range $(-50,50)$; 
- the input values must be numeric characters.

If these conditions are not met, data is not allowed to be recorded in the database. This avoids the recording of erroneous data. Generally, the information is valid if the buttons associated with a meteorological item change their color to green. When the data entered in the diagnosis table is valid and the "Salveaza prognoza" button is pressed, the codes of the phenomena that have occurred will be saved in the database. If no phenomenon is associated with a meteorological field, the value of -99.99 will be recorded in the database.

The recording of the forecasts with different anticipations (Figure 4) is done approximately in the same way as the recording of diagnosis. One of the different aspects is the use of a forecaster's ID. It must consist of four digits. Otherwise, it is not allowed to save the information. This is important for staff evaluation, which will be described in the second part of this paper. Also, another difference is due to the fact that, for the forecasts the selection of the "Conditions" button for the appearance of precipitation is allowed. Day selection will be based on the time at which the 24-hour forecast is valid.

\begin{tabular}{|c|c|c|c|c|c|c|c|c|c|c|c|c|c|}
\hline \multicolumn{3}{|c|}{$\begin{array}{l}\text { ID meteorolog de serviciu: } 0001 \\
\text { Prognoza 24: }\end{array}$} & \multicolumn{3}{|c|}{ Selectati ziua: 6-3-2019 } & \multicolumn{8}{|c|}{ Selectati zona: Republica v } \\
\hline Nebulozitatea & \begin{tabular}{|c|} 
Aparitia \\
precipitatillor
\end{tabular} & \begin{tabular}{|c|} 
Forma \\
precipitatililor
\end{tabular} & \begin{tabular}{|c|} 
Distributia \\
precipitatillor
\end{tabular} & $\left|\begin{array}{|c|}\text { Intensitatea } \\
\text { precipitatilior }\end{array}\right|$ & Vantul & Ceata & Polel & Grindina & Inghet & \multicolumn{2}{|c|}{ Tmin } & \multicolumn{2}{|c|}{$T \max$} \\
\hline \begin{tabular}{|l|l|l|l|}
$S$ & $V$ & $N$ & $A$ \\
\end{tabular} & \begin{tabular}{|l|l|l|}
$D$ & $N$ & $C$ \\
\end{tabular} & BE|P|N|M/PPPN & \begin{tabular}{|l|l|l|} 
& $L$ & $E$ \\
\end{tabular} & s/sc|maclo & CS|SM|MII & \begin{tabular}{|l|l|l|l|} 
& $L$ & $E$ & IT \\
\end{tabular} & \begin{tabular}{|l|l|l|l|} 
& $L$ & $E$ & IT \\
\end{tabular} & \begin{tabular}{|l|l|l|l|} 
& $L$ & $E$ & T \\
\end{tabular} & \begin{tabular}{l|l|l|l|} 
& $L$ & $E$ & $T T$ \\
\end{tabular} & $\min$ & $\max$ & $\min$ & $\max$ \\
\hline \begin{tabular}{|l|l|l|l|} 
& & & 1 \\
\end{tabular} & \begin{tabular}{l|l}
1 \\
\end{tabular} & 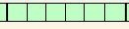 & \begin{tabular}{|l|l|l|} 
& & \\
\end{tabular} & \begin{tabular}{|l|l|l|l|} 
& & & 1 \\
\end{tabular} & \begin{tabular}{ll|l}
1 & 1 \\
\end{tabular} & 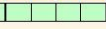 & \begin{tabular}{|l|l|l|l|} 
& & & \\
\end{tabular} & \begin{tabular}{|l|l|l|l|} 
& & & \\
\end{tabular} & 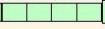 & -3 & 0 & 2 & 5 \\
\hline \multicolumn{14}{|c|}{ Prognoza 48: } \\
\hline Nebulozitatea & \begin{tabular}{|l|} 
Aparitia \\
precipitatillor
\end{tabular} & \begin{tabular}{c|c|} 
Forma \\
precipitatillor
\end{tabular} & \begin{tabular}{|c|} 
Distributia \\
precipitatillor
\end{tabular} & \begin{tabular}{|l|} 
Intensitatea \\
precipitatililor
\end{tabular} & Vantul & Ceata & Polei & Grindina & Inghet & \multicolumn{2}{|c|}{ Tmin } & \multicolumn{2}{|c|}{$\operatorname{Tmax}$} \\
\hline \begin{tabular}{|l|l|l|l|}
$\mathrm{S}$ & $\mathrm{V}$ & $\mathrm{N}$ & $\mathrm{A}$ \\
& & & \\
\end{tabular} & \begin{tabular}{|l|l|l|}
$\mathrm{D}$ & $\mathrm{N}$ & $\mathrm{C}$ \\
& & \\
\end{tabular} & \begin{tabular}{|l|l|l|l|l|} 
B & P & N & PPP & PN \\
& & & & \\
\end{tabular} & 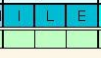 & 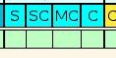 & 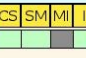 & \begin{tabular}{|l|l|l|l|} 
I & L & E & IT \\
& & & \\
\end{tabular} & \begin{tabular}{|l|l|l|l|} 
& L & E & T \\
\end{tabular} & \begin{tabular}{|l|l|l|l|}
$\mathrm{I}$ & $\mathrm{L}$ & $\mathrm{E}$ & $\mathrm{IT}$ \\
& & & \\
\end{tabular} & \begin{tabular}{|l|l|l|l|}
$\mathrm{I}$ & $\mathrm{L}$ & $\mathrm{E}$ & $\mathrm{T}$ \\
& & & \\
\end{tabular} & \begin{tabular}{|c|}
$\min$ \\
-1 \\
\end{tabular} & \begin{tabular}{|c|}
$\max$ \\
1 \\
\end{tabular} & \begin{tabular}{|c|}
$\min$ \\
2 \\
\end{tabular} & \begin{tabular}{|c|}
$\max$ \\
4
\end{tabular} \\
\hline \multicolumn{14}{|c|}{ Prognoza 72: } \\
\hline Nebulozitatea & \begin{tabular}{|l|} 
Aparitia \\
precipitatillor
\end{tabular} & $\begin{array}{c}\text { Forma } \\
\text { precipitatillor }\end{array}$ & \begin{tabular}{|c|} 
Distributia \\
precipitatililor
\end{tabular} & \begin{tabular}{|l|} 
Intensitatea \\
precipitatiilor
\end{tabular} & Vantul & Ceata & Polei & Grindina & Inghet & \multicolumn{2}{|c|}{ Tmin } & \multicolumn{2}{|c|}{$T \max$} \\
\hline \begin{tabular}{|l|l|l|l|}
$S$ & $V$ & $N$ & $A$ \\
\end{tabular} & \begin{tabular}{|l|l|l}
$D$ & $N$ & $C$ \\
\end{tabular} & \begin{tabular}{|l|l|} 
B & P \\
\end{tabular} & 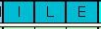 & s|sc|mac|c & CSSM/MII & \begin{tabular}{|l|l|l|l|} 
& $L$ & $E$ & $T$ \\
\end{tabular} & \begin{tabular}{|l|l|l|l|} 
& $L$ & $E$ & IT \\
\end{tabular} & \begin{tabular}{|l|l|l|l|} 
& $L$ & $E$ & \\
\end{tabular} & \begin{tabular}{|l|l|l|l|} 
& $L$ & $E$ & $T T$ \\
\end{tabular} & $\min$ & $\max$ & $\min$ & $\max$ \\
\hline \begin{tabular}{|l|l|l|l|} 
& & & \\
\end{tabular} & \begin{tabular}{l|l|l} 
& 1 & \\
\end{tabular} & 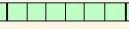 & \begin{tabular}{|l|l|l|} 
& & \\
\end{tabular} & \begin{tabular}{|l|l|l|l}
1 & & & \\
\end{tabular} & \begin{tabular}{l|l|l|l|}
1 & 1 \\
\end{tabular} & \begin{tabular}{l|l|l|l}
1 & & & \\
\end{tabular} & \begin{tabular}{|l|l|l|l|} 
& & & \\
\end{tabular} & \begin{tabular}{|l|l|l|l} 
& & & \\
\end{tabular} & 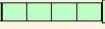 & & $\begin{array}{lll} & -1 \\
\end{array}$ & & 6 \\
\hline
\end{tabular}

Figure 4. The interface for forecast data input in the database.

The scores are calculated automatically using the computation method used within the National Meteorological Administration since 1996 (Diaconu, 2001). These are computed for each meteorological item, for each anticipation. The results are saved in the "SCORES" table.

The application allows to record past data. For this, it's important to save the forecasts first and the diagnosis later. This is due to the fact that, for calculating the scores, the query of the database is made only when the diagnosis is recorded. 


\subsection{Visualization of scores}

The graphical interface for viewing the scores has been developed to perform multiple functions, allowing the results to be visualized in both tabular and graphical format (Figure 5).

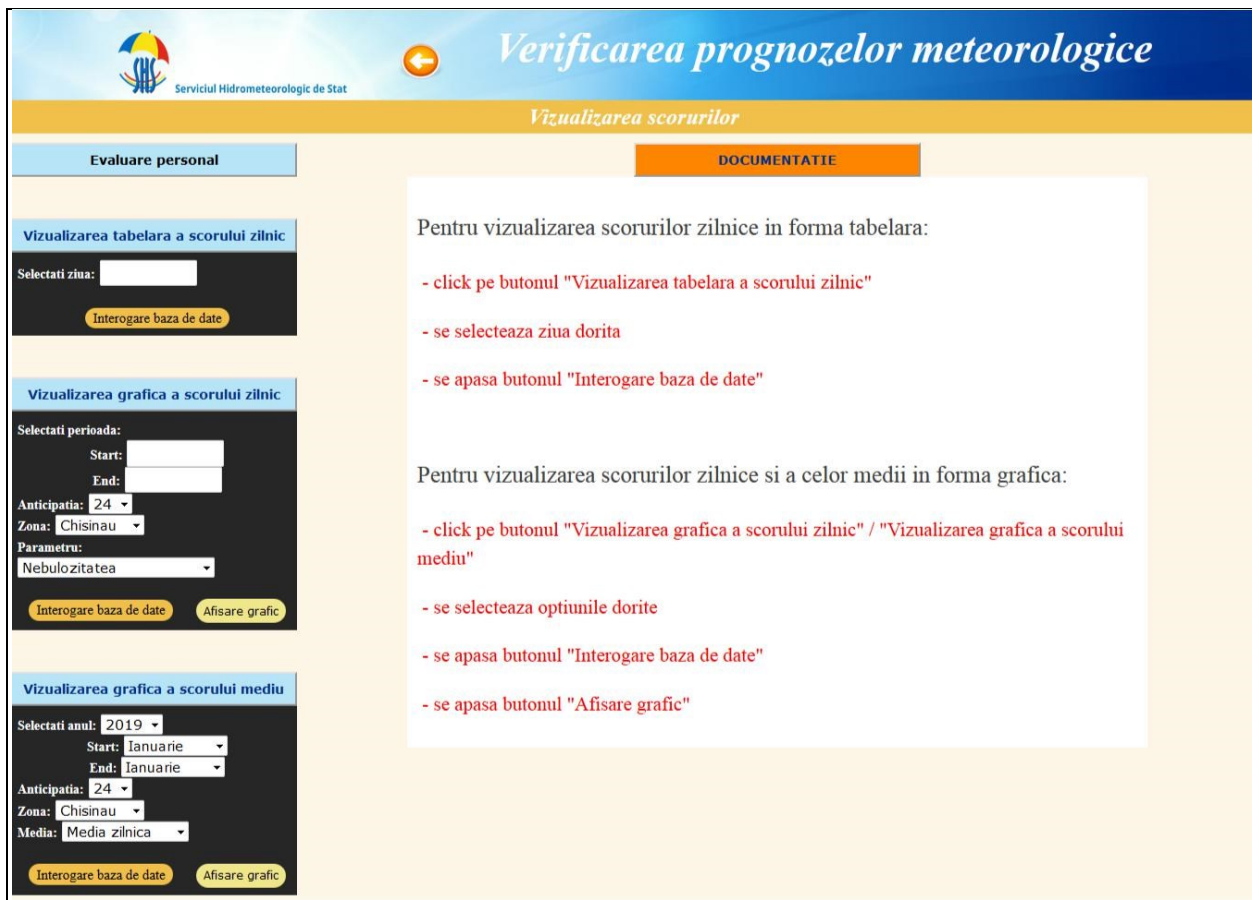

Figure 5. Graphical interface for visualizing scores.

The graphical interface contains the following elements:

- On the header page, there is a button which directs the user to the official site of the Hydrometeorological Service of the Republic of Moldova. Next to it, is also the user's targeting button to the previous page.

- A "Documentation" button is located at the top-right of the page. By clicking on this button, a window will appear on the screen showing the steps to be made for displaying the scores.

- On the left-hand side of the page there are four blue buttons. The first of them is meant for staff evaluation. The other three are for score visualization.

In order to view the scores in tabular form, after taking the steps shown in Figure 5, three tables will be displayed on the screen. These show the calculated scores for the two regions, Chisinau and Republic, respectively for the whole 
country (Figure 6). The scores are calculated for all three forecasts with different ranges. If there are no diagnostics or forecast information for one of the two regions, the message "Error! There is no complete set of data in the database!" will appear. No evaluation has been made for those meteorological elements where the calculated scores values are -99.99 . This means that no associated phenomenon has occurred.

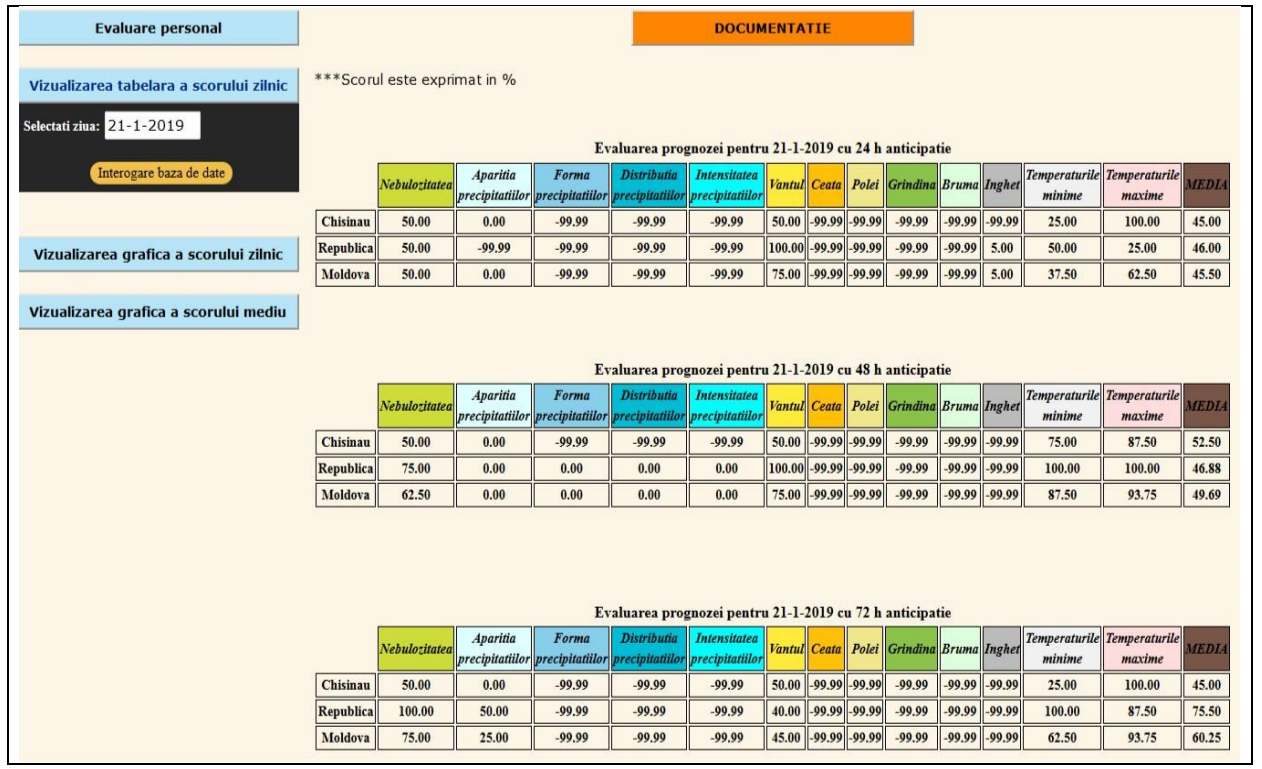

Figure 6. Display of the scores in tabular form.

For the visualization of the daily score in graphical form, complete the desired period, select the range, the region and the parameter, press the "Database query" button, and then the "Graphic display" button. A graph as shown in Figure 7 will appear on the screen. This contains the scores values for the selected period. The value "-1" is assigned for the situations when the meteorological item has not been evaluated - this could happen for several meteorological variables, in particular precipitation and special meteorological phenomena. This mode of representation allows to identify the days when no phenomena associated with the respective meteorological elements occurred. Positioning the cursor on one of the columns displayed, a box showing the day and the value of the calculated score appears.

In order to view the average score in graphics, choose the blue button at the bottom of the graphical interface. With respect to the average score, it can be 
calculated daily, monthly, for a period of 3 months, 6 months, 9 months or yearly.

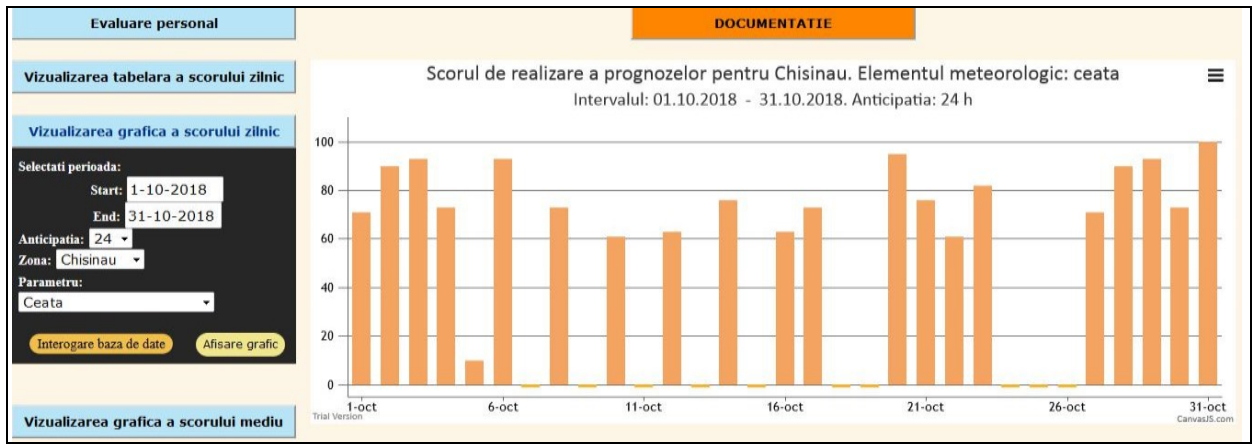

Figure 7. Display of the daily scores in graphical form.

For a graphical view of the daily average score, after following the steps shown in the bottom of Figure 5, a graph will appear on the screen (Figure 8). If there is no full set of data for the selected period in the database, the message "For the selected period in the database, the data set is not complete!" will be shown below the graph title.

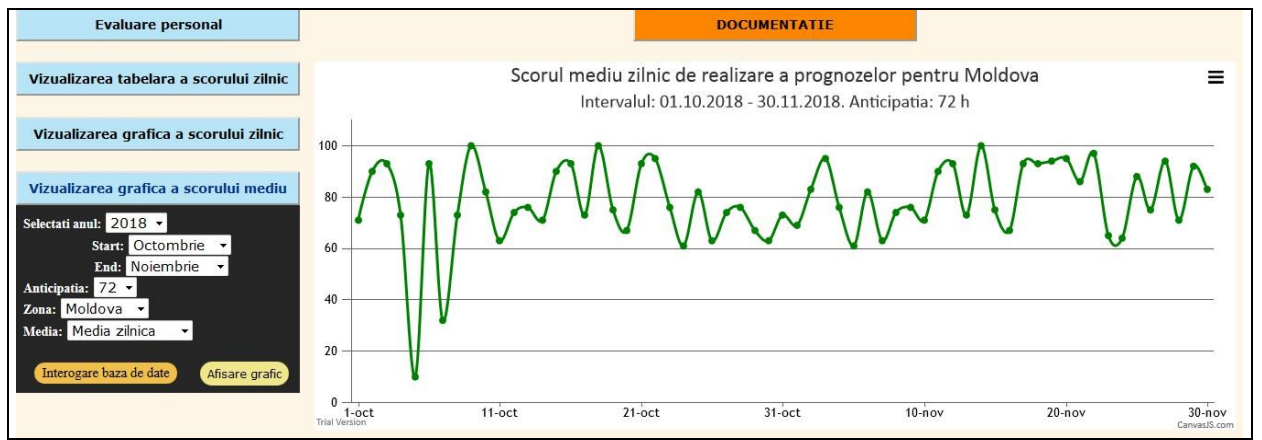

Figure 8. Display of the daily average score in graphical form.

In the case of graphical view of the average monthly score, it is possible to select a larger number of months. Pressing the "Graphic display" button will display a graph where the monthly score values are represented by columns.

In the case of graphical visualization of the average score for the other intervals, like 3 months, 6 months, 9 months or one year, a very important aspect is that the selected period must coincide with the number of months of 
the chosen interval. For example, if a 6-month interval is selected and it is desired to see the average score for every 3 months, the message "You did not select a 3-month period!" will appear on the screen. If the interval selection is correct, pressing the "Graphic display" button, a graph where the value of the calculated score for the selected period, represented by a column, will be shown on the screen (Figure 9).

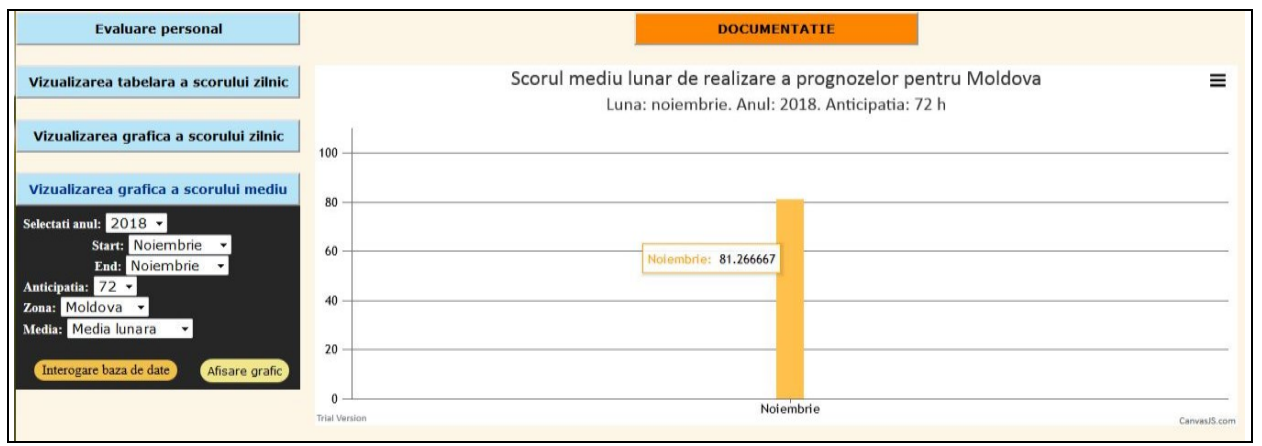

Figure 9. Display of the monthly average score in graphical form.

If there is no complete data set for the selected period in the database, the message "No calculations for the selected period of time!" appears on the screen. The application allows to save the graph in jpg or png format.

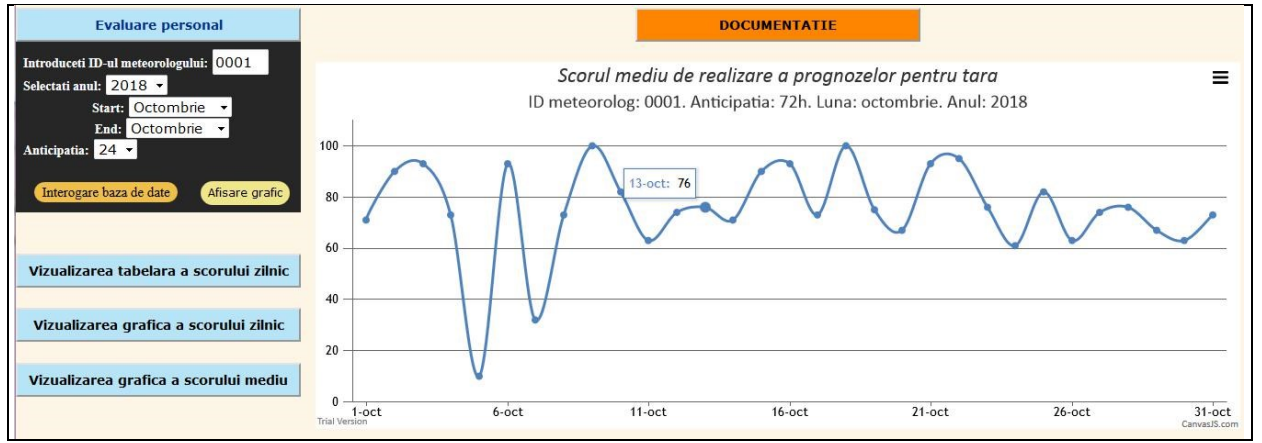

Figure 10. Staff evaluation.

Another important use of this system is the posibility to evaluate the staff of the weather forecasting center. This can be done on the first blue button on the left part of the page, "Staff evaluation" section. Here, one may enter the forecaster's ID, select the period (the shortest interval that can be selected is one 
month) and forecast range. After pressing the "Database query" button, and then the "Graphic display" button a graph as shown in Figure 10 will appear on the screen. Thus, the quality of the forecasts elaborated by each one of the staff of the forecasting center can be analyzed.

\section{Conclusions}

The verification system described in this paper is an application developed to evaluate the weather forecasts. Both graphical interfaces, for recording the information (diagnosis and forecasts) into the database and viewing the verification results, greatly simplify user interaction with the database where the information is saved.

The verification database is created automatically on the first use of this application. Within this database, five tables are generated to record diagnoses, forecasts with different ranges (24, 48, 72 hours) and scores. If no phenomenon is associated with a meteorological field, the value saved into database is 99.99. In this way, the possibility to evaluate phenomena which have not occurred is eliminated.

Another advantage of this application is that it creates an orderly work environment. The graphical interface for viewing scores allows both tabular and graphical views. There is also the possibility of evaluating the authorized staff within the institution.

\section{References}

1. Birsan M.V. (2015), Trends in Monthly Natural Streamflow in Romania and Linkages to Atmospheric Circulation in the North Atlantic. Water Resources Management 29(9): 3305-3313. doi: 10.1007/s11269-015-0999-6

2. Birsan M.V., Marin Lenuta, Dumitrescu A. (2013), Seasonal changes in wind speed in Romania. Romanian Reports in Physics 65(4): 1479-1484.

3. Birsan M.V., Micu Dana-Magdalena, Nita A.I., Mateescu E., Szép R., Keresztesi Á. (2019), Spatio-temporal changes in annual temperature extremes over Romania (1961-2013). Romanian Journal of Physics 64(7-8): 816.

4. Busuioc A., Birsan M.V., Carbunaru D, Baciu Mădălina, Orzan Alina (2016). Changes in the large-scale thermodynamic instability and connection with rain shower frequency over Romania. Verification of the Clausius-Clapeyron scaling. International Journal of Climatology 36(4): 2015-2034. doi: 10.1002/joc.4477

5. Colls K., Mason I.B., Daw F.A. (1981), A forecast verification procedure for public weather forecasts, Australian Meteorological Magazine, 29(1): 9-23.

6. Corobov R., Sheridan S., Overcenco A., Terinte N. (2010) Air temperature trends and extremes in Chisinau (Moldova) as evidence of climate change. Climate Research 2: 247-256. doi: 10.3354/cr00922 
7. Diaconu O., Sima A. (2001), An objective method for evaluating short- and midrange weather forecasts. Yearly Scientific Conference of the National Meteorological Administration. Bucharest, 2001 (in Romanian).

8. Dobrinescu A., Busuioc Aristita, Birsan M.V., Dumitrescu A. (2015), Changes in thermal discomfort indices in Romania and responsible large-scale mechanisms. Climate Research 64(3): 213-226. doi: 10.3354/cr01312

9. Jolliffe I.T., Jolliffe N. (2012), Assessment of descriptive weather forecasts. Weather, 51(12): 391-396. doi: 10.1002/j.1477-8696.1997.tb06261.x

10. Jolliffe I.T., Stephenson D.B. (Eds.) (2011), Forecast Verification: A Practitioner's Guide in Atmospheric Science. 2nd Ed.. Wiley and Sons Ltd, 292pp.

11. Manea A., Birsan M.V., Tudorache G., Cărbunaru Felicia (2016), Changes in the type of precipitation and associated cloud types in Eastern Romania (19612008). Atmospheric Research 169: 357-365. doi: 10.1016/j.atmosres.2015.10.020

12. Mihai G., BîrsanM.V., Dumitrescu A., Alexandru A., Mirancea I., Ivanov P., Stuparu E., Teodosiu M., Daia M. (2018a), Adaptive genetic potential of European silver fir in Romania in the context of climate change. Annals of Forest Research 61(1): 95-108. DOI: 10.15287/afr.2018.1021

13. Mihai G., Mirancea I., Birsan M.V., Dumitrescu A. (2018b), Patterns of genetic variation in bud flushing of Abies alba populations. iForestBiogeosciences and Forestry 11(2): 284-290. DOI: 10.3832/ifor2314-011

14. Potop V., Soukup J. (2009), Spatiotemporal characteristics of dryness and drought in the Republic of Moldova. Theoretical and Applied Climatology. 96: 305-318. doi: 10.1007/s00704-008-0041-5

C 2020 by the authors. Licensee UAIC, Iasi, Romania. This article is an open access article distributed under the terms and conditions of the Creative Commons Attribution (CC BY-NC-ND) license (https:// creativecommons.org/licenses/by-nc-nd/4.0). 
